\title{
Formulation and In-vitro Evaluation of Mouth Dissolving Tablets of Mirtazapine
}

\author{
Tejwasana, H Padma Latha, Janmajoy Banerjee and Ranabir Chanda* \\ Gyana Jyothi College of Pharmacy, India \\ *Corresponding author: Ranabir Chanda, Gyana Jyothi College of Pharmacy, Uppal Bus Dept, Hyderabad, India

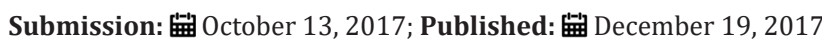

\begin{abstract}
In our present study we want to develop mouth dissolving tablets of mirtazapine. Mirtazapine, vivasol, explotab, camphor, magnesium stearate, talc, microcrystalline cellulose were used for the preparation of the tablets. The tablets were prepared by direct compression method and bulk density, tapped density, angle of repose, carr's index, hausners ratio, weight variation, thickness, hardness, friability and in vitro drug release were evaluated. Formulation F6 was considered as optimized formulations for mouth dissolving tablet of mirtazapine.
\end{abstract}

Keywords: Mirtazapine; Vivasol; Explotab; Camphor; Mouth dissolving tablets

\section{Introduction}

Mouth dissolving tablets as a novel dosage form, have several characteristics to distinguish them from the more traditional dosage forms. These tablets increased bioavailability compared to traditional tablets [1]. The oral cavity is an attractive site for the administration of drugs because of ease of administration. Various dosage forms like Tablets, Capsules, and Liquid preparations are administered by oral route. During the last decade, mouth dissolving tablet (MDT) technologies that make tablets disintegrate in the mouth without chewing and additional water intake have drawn a great deal of attention [2]. The mouth dissolving tablets or MDT is also known as fast melting, fast dispersing, rapid dissolve, rapid melt, and or quick disintegrating tablet. Orally disintegrating tablets provide an advantage particularly for pediatric and geriatric populations who have difficulty in swallowing conventional tablets and capsules. Additionally, pediatric patients may suffer from ingestion problems as a result of underdeveloped muscular and nervous control. Moreover, patients traveling with little or no access to water, limit utility of orally administered conventional tablets or capsules. Mouth dissolving of tablet results in quick dissolution and rapid absorption which provide rapid onset of action. Moreover, drug candidates that undergo pre-gastric absorption when formulated as mouth dissolving tablets (MDT) may show increased oral bioavailability. It provides good stability, accurate dosing, easy manufacturing $[3,4]$. Mirtazapine is a tetra-cyclic anti-depressant. It is contra indicated in patients with hyper sensitivity to drug [5].

\section{Materials and Methods}

\section{Materials}

Mirtazapine was collected from Sura Lab., Hyderabad, India as a gift sample. Vivasol, explotab, camphor, microcrystalline cellulose, magnesium stearate, and talc were purchased from Merck Specialities Pvt. Ltd., Mumbai, India.

\section{Methods}

Preparation of mirtazapine mouth dissolving tablets by sublimation method: Drug different concentrations of super disintegrate and optimized concentration of camphor were accurately weighed and passed through a 20-mesh screen to get uniform size particles and mixed in a glass mortar for 15 minutes. The obtained blend was lubricated with magnisium stearate and talc was added and mixing was continued for further 5 minutes. The resultant mixture was directly compressed into tablets by using $5 \mathrm{~mm}$ round flat faced punch of rotary tablet compression machine. The formulations prepared for mouth dissolving tablet of Mirtazapine was given in (Table 1) [6].

\section{Pre compression evaluation parameters}

Bulk density $\left(D_{b}\right)$ : It is the proportion of aggregate mass of powder to the mass volume of powder. It was measured by pouring the weight powder (went through sieve number 20) into a measuring chamber and introductory weight was noted. This underlying volume is known as the mass volume. From this the mass thickness is ascertained by the equation specified underneath. It is communicated in $\mathrm{g} / \mathrm{ml}$ and is given by,

$$
\mathrm{D}_{\mathrm{b}}=\mathrm{M} / \mathrm{V}_{\mathrm{b}}
$$

Where, $\mathrm{M}$ is the mass of powder, $\mathrm{V}_{\mathrm{b}}$ is the mass volume of the powder.

Tapped density $\left(D_{t}\right)$ : It is the proportion of aggregate mass of the powder to the tapped volume of the powder. Volume was 
measured by tapping the powder for 750 times and the tapped volume was noted if the distinction between these two volumes is fewer than $2 \%$. In the event that it is over $2 \%$, tapping is preceded for 1250 times and tapped volume was noted. Tapping was preceded until the point that the distinction between progressive volumes is under $2 \%$ (in a mass thickness mechanical assembly). It is communicated in $\mathrm{g} / \mathrm{ml}$ and is given by,

Table 1: Formulation of Sublimation Mouth Dissolving Tablets

\begin{tabular}{|c|c|c|c|c|c|c|c|c|c|}
\hline Ingredients (mg) & F1 & F2 & F3 & F4 & F5 & F6 & F7 & F8 & F9 \\
\hline Mirtazapine & 15 & 15 & 15 & 15 & 15 & 15 & 15 & 15 & 15 \\
\hline Vivasol & 5 & 10 & 15 & -- & -- & -- & 2.5 & 5 & 7.5 \\
\hline Explotab & -- & -- & -- & 5 & 10 & 15 & 2.5 & 5 & 7.5 \\
\hline Camphor & 10 & 10 & 10 & 10 & 10 & 10 & 10 & 10 & 10 \\
\hline Mg.stearate & 2 & 2 & 2 & 2 & 2 & 2 & 2 & 2 & 2 \\
\hline Talc & 2 & 2 & 2 & 2 & 2 & 2 & 2 & 2 & 2 \\
\hline Microcrystalline cellulose & QS & QS & QS & QS & QS & QS & QS & QS & QS \\
\hline Total weight & 100 & 100 & 100 & 100 & 100 & 100 & 100 & 100 & 100 \\
\hline
\end{tabular}

$$
\mathrm{D}_{\mathrm{t}}=\mathrm{M} / \mathrm{V}_{\mathrm{t}}
$$

Where, $\mathrm{M}$ is the mass of powder, $\mathrm{V}_{\mathrm{t}}$ is the tapped volume of the powder.

Angle of repose $(\boldsymbol{\theta})$ : The friction forces in a loose powder can be measured by the angle of repose (q). It is an indicative of the flow properties of the powder. It is defined as maximum angle possible between the surface of the pile of powder and the horizontal plane

$$
\theta=\tan ^{-1}(\mathrm{~h} / \mathrm{r})
$$

Where,

$\theta$ is the angle of repose, $\mathrm{h}$ is the height in $\mathrm{cm}$ and $\mathrm{r}$ is the radius in $\mathrm{cm}$.

The powder mixture was allowed to flow through the funnel fixed to a stand at definite height $(\mathrm{h})$. The angle of repose was then calculated by measuring the height and radius of the heap of powder formed. Care was taken to see that the powder particles slip and roll over each other through the sides of the funnel. Relationship between angle of repose and powder flow property.

Carr's index (or) \% compressibility: It indicates powder flow properties. It is expressed in percentage and is give by,

$$
I=\frac{D_{t}-D_{b}}{D_{t}} \times 100
$$

Where,

$D_{t}$ is the tapped density of the powder and $D_{b}$ is the bulk density of the powder.

Hausners ratio: Hausner ratio is an indirect index of ease of powder flow. It is calculated by the following formula.

$$
\text { Hausner ratio }=\frac{D_{t}}{----}
$$

Where, $D_{t}$ is the tapped density, $D_{b}$ is the bulk density.

Lower Hausners ratio $(<1.25)$ indicates better flow properties than higher ones (>1.25) [7].

\section{Post compression evaluation parameters}

Weight variation: Twenty tablets were selected randomly from the lot and weighted individually to check for weight variation.

Hardness: Hardness or tablet crushing strength (fc), the force required to break a tablet in a diametric compression was measured using Monsanto tablet hardness tester. It is expressed in $\mathrm{kg} / \mathrm{cm}^{2}$.

Thickness: Three tablets were selected randomly from each batch and thickness was measured by using digital micrometer.

4.4.4.Friability (F): Friability of the tablet determined using Roche friabilator. This device subjects the tablet to the combined effect of abrasion and shock in a plastic chamber revolving at $25 \mathrm{rpm}$ and dropping a tablet at the height of 6 inches in each revolution. Pre weighed sample of tablets was placed in the friabilator and were subjected to the 100 revolutions. Tablets were dusted using a soft muslin cloth and reweighed. The friability (F) is given by the formula [8].

$$
\mathbf{F}=\frac{\mathbf{W}_{\text {initial }}-\mathbf{W}_{\text {final }}}{-\mathbf{W}_{\text {initial }}} \times 100
$$

\section{Determination of drug content in tablets}

Three tablets were randomly selected, weighed and finely powdered and quantity of powder equivalent to one tablet was added to $100 \mathrm{ml}$ of $\mathrm{pH} 6.8$ phosphate buffer in a conical flask. A conical flask was then placed on a rotary shaker.

An aliquot of solution was centrifuged and supernatant was filtered through a $0.22 \mu$ filter. Absorbance of the resulted supernatant solution was measured using U.V Visible double beam spectrophotometer at respective wavelength against $\mathrm{pH} 6.8$ phosphate buffer as blank. Concentrations and amount of drug present in one tablet were calculated with the help of calibration curves.

Conc $=$ Abs $/$ Slope 
Drug content in $\mathrm{mg} /$ tablet $=$ conc. $\mu \mathrm{g} / \mathrm{ml} \times$ dilution factor

$\%$ Drug content $=$ drug content in mg x100/label claim.

\section{Determination of wetting time}

A piece of tissue paper folded twice was placed in a small petridish containing $6 \mathrm{ml}$ of water. A water-soluble dye phenolphthalein was added to the petridish. The dye solution was used to identify the complete wetting of the tablet surface. A tablet was carefully placed on the surface of tissue paper in the petridish at room temperature.

The time required for water to reach the upper surface of the tablets and completely wet them was noted as the wetting time. To check for reproducibility, the measurements were carried out in triplicates $(n=3)$. The wetting time was recorded using a stopwatch.

\section{Determination of water absorption ratio (R)}

The weight of the tablet before keeping in the petridish was noted $\left(\mathrm{W}_{\mathrm{b}}\right)$ using digital balance. The wetted tablet from the petridish was taken and reweighed $\left(\mathrm{W}_{\mathrm{a}}\right)$ using the same. The Water absorption ratio, $\mathrm{R}$, was determined according to the following equation:

$\mathrm{R}=\left(\mathrm{W}_{\mathrm{a}}-\mathrm{W}_{\mathrm{b}}\right) / \mathrm{W}_{\mathrm{b}} \mathrm{X} 100$

Where, $\mathrm{W}_{\mathrm{a}}=$ Weight of the tablet after absorption

$\mathrm{W}_{\mathrm{b}}=$ Weight of the tablet before absorption.

\section{Determination of in-vitro dispersion time}

In- vitro dispersion time was determined by placing one tablet in a beaker containing $10 \mathrm{ml}$ of $\mathrm{pH} 6.8$ phosphate buffer at $37 \pm 0.5$
${ }^{\circ} \mathrm{C}$ and the time required for complete dispersion was determined. To check for reproducibility, the measurements were carried out in triplicates $(n=3)$. The dispersion time was recorded using a stopwatch [9].

\section{Determination of drug- excipient compatibility studies by FTIR}

The compatibility between the pure drug and excipients was detected by FTIR spectra obtained on Bruker FTIR Germany (Alpha $\mathrm{T})$. The spectra were recorded over the wave number of 4000 to $5500 \mathrm{~cm}-1$ [10].

\section{Determination of In-vitro drug release study}

Dissolution test was carried out by using USP type II apparatus. The paddle was rotated at 50rpm. pH 6.8 phosphate buffer was used as dissolution medium $(900 \mathrm{ml})$ and was maintained at $37 \pm 1$ ${ }^{\circ} \mathrm{C}$. Samples of $5 \mathrm{ml}$ were withdrawn at predetermined intervals, filtered and replaced with $5 \mathrm{ml}$ of fresh dissolution medium. The collected samples were suitably diluted with dissolution fluid, where ever necessary and were analyzed for the drug at respective wavelength by using UV spectrophotometer [6].

\section{Results and Discussions}

The data were shown in Table 2. The values for angle of repose were found below $28^{\circ} \mathrm{C}$. Bulk density and tapped density of various formulations were found to be in the range of 0.61 to $0.72(\mathrm{gm} / \mathrm{ml})$ and 0.71 to $0.81(\mathrm{gm} / \mathrm{ml})$ respectively. Carr's index of the prepared blends was less than $18 \%$ and Hausners ratio was less than 1.25. From these results it was concluded that the powder blends had good flow properties and these can be used for tablet manufacture (Table 2).

Table 2: Pre-compression Parameters of Different Formulations of Mirtazapine.

\begin{tabular}{|c|c|c|c|c|c|}
\hline Formulations & Bulk Density (gm/ml) & Tap Density (gm/ml) & Carr's Index (\%) & Hausner Ratio & Angle Of Repose( $\boldsymbol{\theta})$ \\
\hline F1 & 0.68 & 0.79 & 13.92 & 1.16 & 26.38 \\
\hline F2 & 0.72 & 0.81 & 11.11 & 1.12 & 24.12 \\
\hline F3 & 0.65 & 0.75 & 13.33 & 1.13 & 26.38 \\
\hline F4 & 0.69 & 0.78 & 11.53 & 1.19 & 27.01 \\
\hline F5 & 0.66 & 0.79 & 16.45 & 1.14 & 26.97 \\
\hline F6 & 0.62 & 0.71 & 12.67 & 1.13 & 26.94 \\
\hline F7 & 0.65 & 0.74 & 15.27 & 1.17 & 25.16 \\
\hline F9 & 0.61 & 0.72 & 14.86 & & 27.09 \\
\hline
\end{tabular}

Tablets of each batch were subjected to weight variation test, difference in weight and percent deviation was calculated for each tablet. The weight of the tablet is approximately in range of 96.47 to $100.34 \mathrm{mg}$. The permissible limit is $\pm 10 \%$. The results of the test showed that, the tablet weights were within the pharmacopoeia limit. Hardness of the three tablets of each batch was checked by using Monsanto hardness tester. The results showed that the hardness of the tablets is in range of 2.4 to $2.8 \mathrm{~kg} / \mathrm{cm}^{2}$, which was within I.P limits. Thickness of three tablets of each batch was checked by using digital micrometer. The result showed that thickness of the tablet is raging from 2.34 to 2.81. Tablets of each batch were evaluated for percentage friability. The friability of all the formulations lies in the range of 0.36 to $0.81 \%$ which was less than $1 \%$ as per official requirement of IP indicating a good mechanical resistance of tablets.

Drug content studies were performed for the prepared formulations. From these studies, it was concluded that all the formulations were showing the \% drug content values within 95.91 to $99.63 \%$. All data are shown in (Table 3). 
Table 3: Post-compression Parameters of Different Formulations of Mirtazapine.

\begin{tabular}{|c|c|c|c|c|c|}
\hline Formulation & Weight Variation (mg) & Hardness $\left(\mathrm{kg} / \mathrm{cm}^{2}\right)$ & Thickness (mm) & Friability (\%) & Drug Content (\%) \\
\hline $\mathrm{F} 1$ & 99.66 & 2.8 & 2.81 & 0.51 & 96.34 \\
\hline $\mathrm{F} 2$ & 98.35 & 2.5 & 2.46 & 0.36 & 99.58 \\
\hline F3 & 96.47 & 2.6 & 2.91 & 0.49 & 98.14 \\
\hline $\mathrm{F} 4$ & 99.41 & 2.8 & 2.62 & 0.56 & 96.82 \\
\hline F5 & 100.24 & 2.6 & 2.74 & 0.81 & 95.91 \\
\hline F6 & 99.75 & 2.4 & 2.34 & 0.44 & 98.63 \\
\hline F7 & 97.14 & 2.6 & 2.29 & 0.47 & 98.48 \\
\hline F8 & 99.18 & 2.6 & 2.64 & 0.59 & 96.49 \\
\hline F9 & 100.34 & 2.5 & 2.41 & 0.61 & 99.16 \\
\hline
\end{tabular}

Tablets of each batch were evaluated for in-vitro disintegration time. The results showed that the disintegration time of prepared tablets were in the range 11.28 to 29.22 seconds. Wetting time to the time required to wet completely when kept motionless on the tissue paper in a petridish. All the mouth dissolving tablets formulations of mirtazapine were evaluated for their wetting time as per the procedure described in the methodology section. The wetting time for all the formulations was in the range of 8.49 to 26.14seconds.

Table 4: In- vitro Disintegration Time, Wetting Time, Dispersion Time, \%Water Absorption Ratio of Different Formulations of Mirtazapine.

\begin{tabular}{|c|c|c|c|c|}
\hline Formulation & Disintegration Time (sec) & Wetting time (sec) & In-vitro Dispersion Time (sec) & \%Water Absorption Ratio \\
\hline F1 & 29.22 & 26.14 & 32.19 & 94 \\
\hline F2 & 26.18 & 23.14 & 28.21 & 97 \\
\hline F3 & 21.24 & 18.16 & 23.18 & 98 \\
\hline F4 & 18.13 & 16.49 & 20.14 & 96 \\
\hline F5 & 16.24 & 14.22 & 19.36 & 99 \\
\hline F6 F7 & 12.41 & 10.14 & 14.18 & 96 \\
\hline F8 & 16.49 & 13.28 & 19.14 & 98 \\
\hline F9 & 14.19 & 11.46 & 16.21 & 99 \\
\hline
\end{tabular}

Table 5: Percentage of Drug Release of Different Formulations of Mirtazapine By In-vitro Dissolution Studies.

\begin{tabular}{|c|c|c|c|c|c|c|c|c|c|}
\hline Time(minutes) & F1 & F2 & F3 & F4 & F5 & F6 & F7 & F8 & F9 \\
\hline 0 & 0 & 0 & 0 & 0 & 0 & 0 & 0 & 0 & 0 \\
\hline 5 & 25.3 & 43.5 & 34.91 & 33.16 & 45.23 & 49.48 & 17.8 & 19.07 & 24.45 \\
\hline 10 & 47.6 & 66.3 & 46.45 & 41.03 & 61.57 & 69.33 & 24.72 & 23.75 & 38.97 \\
\hline 15 & 56.3 & 75.2 & 59.23 & 53.15 & 73.61 & 80.56 & 33.33 & 40.46 & 41.28 \\
\hline 20 & 67.3 & 89.8 & 72.34 & 66.28 & 89.21 & 99.31 & 42.58 & 50.25 & 51.53 \\
\hline 30 & 80.3 & 99.46 & 85.73 & 79.72 & 99.46 & & 52.05 & 67.1 & 72.04 \\
\hline 45 & 95.1 & & 99.47 & 87.43 & & & 69.47 & 79.3 & 87.1 \\
\hline 60 & 95.7 & & & 99.75 & & & 82.34 & 90.34 & 98.6 \\
\hline
\end{tabular}

In-vitro dissolution studies of all formulations are depicted in Table 5. The drug release from formulation F6 was 99.31 at 20minutes. F6 showed the desired drug release profile and for this reasons it was considered as best and optimized formulation among all the nine formulations (Table 5).

FTIR studies of pure mirtazapine and optimized formulation (F6) were performed and it was confirmed that there was no interactions between drug and excipients (Figure 1,2).
The in- vitro dispersion time for all formulation was found to be in a range of 13.46 to 32.19 seconds. All the formulations were evaluated for water absorption ratio according to the procedure described in methodology section and the results are shown in table 8. The maximum water absorption ratio was shown by formulation F6 and F9 i.e., 99\%. Water absorption ratio is directly proportional to dissolution rate profile as higher the water absorption ratio faster the dissolution. All results were shown in (Table 4). 


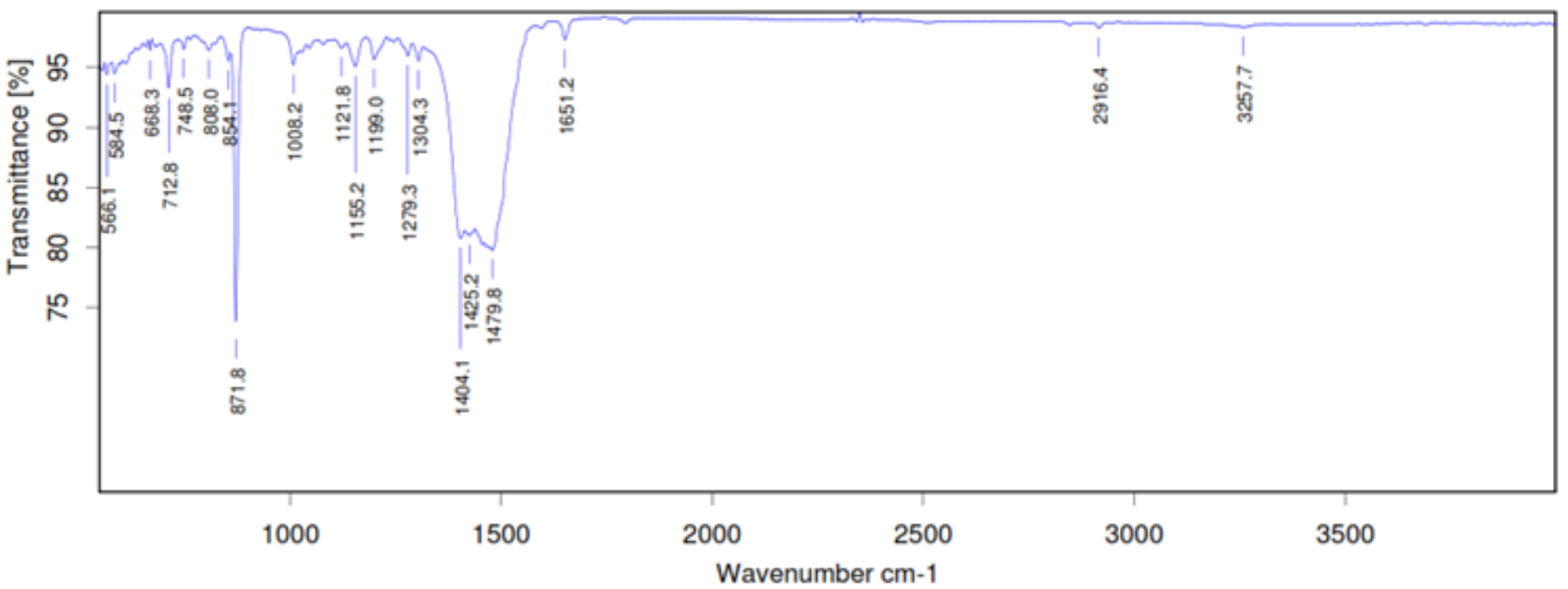

Figure 1: FTIR Spectrum of Mitrazapine.

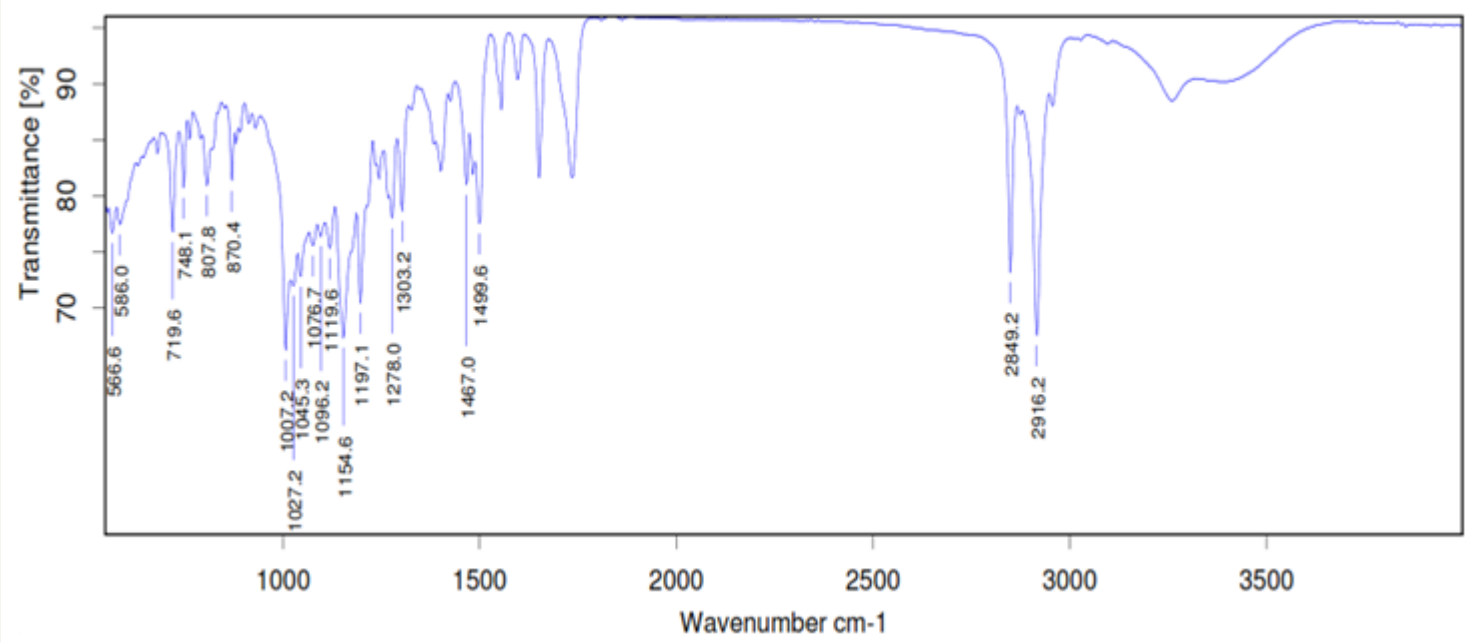

Figure 2: FTIR Spectrum of Optimized Formulation (F6) of Mitrazapine.

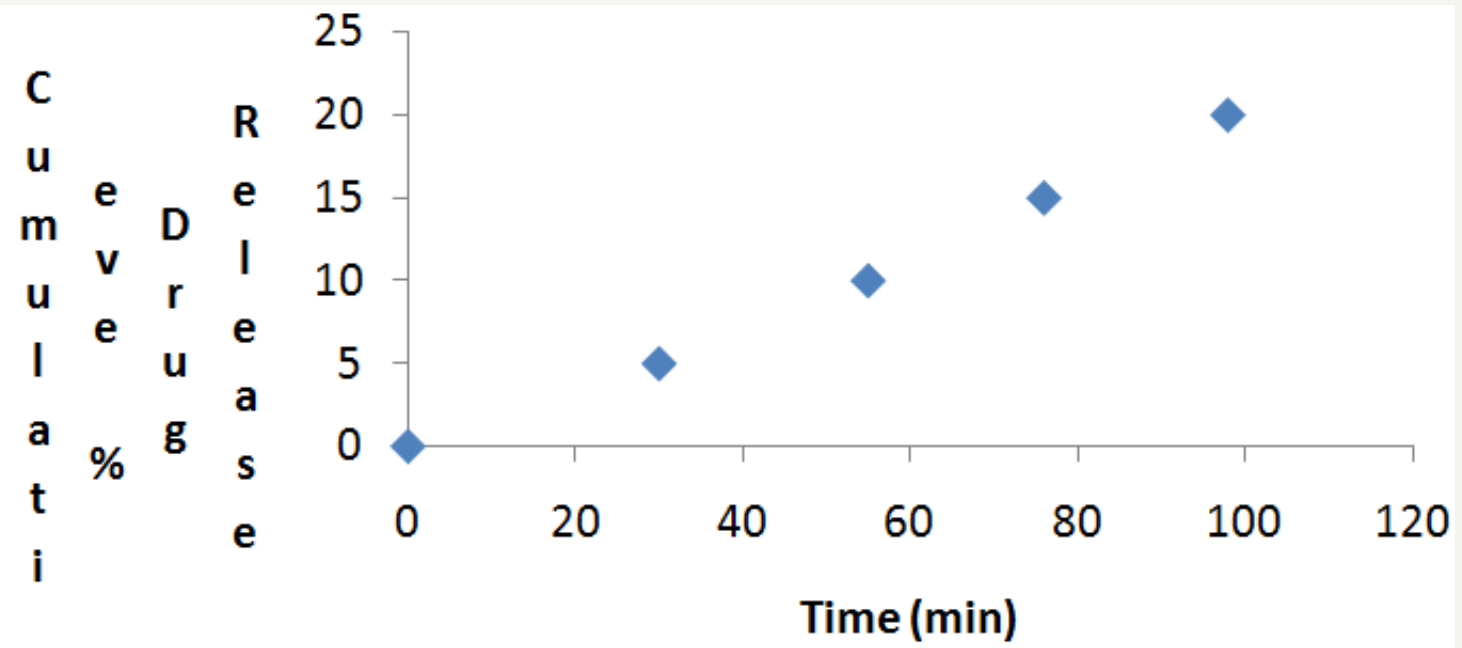

Figure 3: Cumulative Percentage of Drug Release of Formulation F6 after storage for One Month at $45^{\circ} \mathrm{C}$. 


\section{Conclusion}

The present study concludes that delivery of drug from mouth dissolving tablets of Mirtazapine can be a good way get quick onset of action. Whereas from the dissolution studies it was evident that the formulation (F6) showed better and optimized and desired drug release pattern i.e., $99.31 \%$ in 20 minutes. In this formulation super disintegrant explotab and drug mirtazapine were used in 1:1 ratio. While stability studying at $45{ }^{\circ} \mathrm{C}$ for one month, no significant changes were observed.

\section{Acknowledgement}

We cordially acknowledge authority of Gyana Jyothi College of Pharmacy, Hyderabad, India for providing laboratory facility for our research work.

\section{References}

1. Van Duuren BL, Goldschmidt BM (1966) Carcinogenicity of epoxides, lactones, and peroxy compounds. 3. Biological activity and chemical reactivity. J Med Chem 9(1): 77-79.

2. Shi Y, Zhou CH (2011) Synthesis and evaluation of a class of new coumarin triazole derivatives as potential antimicrobial agents. Bioorg Med Chem Lett 21(3): 956-960.

3. Montagner C, Souza SM, Groposoa C, Delle Monache F, Smania EF, et al. (2008) Anti-fungal activity of coumarins. Journal of biosciences 63(1-2): 21-28.

4. Hwu JR, Singha R, Hong SC, Chang YH, Das AR, et al. (2008) Synthesis of new benzimidazole-coumarin conjugates as anti-hepatitis $\mathrm{C}$ virus agents. Antiviral Res 77(2): 157-162.

5. Cardoso SH, Barreto MB, Lourenco MC, Henriques M, Candea AL, et al. (2011) Anti-tubercular activity of new coumarins. Chemical biology \& drug design 77(6): 489-493.

6. Huang F, Tang LH, Yu LQ, Ni YC, Wang QM, et al. (2006) In vitro potentiation of antimalarial activities by daphnetin derivatives against Plasmodium falciparum. Biomed Environ Sci 19(5): 367-370.

7. Kontogiorgis CA, Hadjipavlou-Litina DJ (2004) Synthesis and biological evaluation of novel coumarin derivatives with a 7-azomethine linkage. Bioorg Med Chem Lett 14(3): 611-614.

8. Jung JC, Lee JH, Oh S, Lee JG, Park OS (2004) Synthesis and antitumor activity of 4-hydroxycoumarin derivatives. Bioorg Med Chem Lett 14(22): 5527-5531.

9. Kostova I, Raleva S, Genova P, Argirova R (2006) Structure-Activity Relationships of Synthetic Coumarins as HIV-1 Inhibitors. Bioinorg Chem Appl 2006:68274.

10. Lacy A, Kennedy OR (2004) Studies on coumarins and coumarin-related compounds to determine their therapeutic role in the treatment of cancer. Curr Pharm Des 10(30): 3797-3811.

11. Kulkarni MV, Kulkarni GM, Lin CH, Sun CM (2006) Recent advances in coumarins and 1-azacoumarins as versatile biodynamic agents. Curr Med Chem 13(23): 2795-2818.

12. Bhattacharyya SS, Paul S, Mandal SK, Banerjee A, Boujedaini N, et al. (2009) A synthetic coumarin (4-Methyl-7 hydroxy coumarin) has anticancer potentials against DMBA-induced skin cancer in mice. Eur J Pharmacol 614(1-3): 128-136.

13. Weber US, Steffen B, Siegers CP (1998) Antitumor-activities of coumarin, 7-hydroxy-coumarin and its glucuronide in several human tumor cell lines. Res Commun Mol Pathol Pharmacol 99(2): 193-206.

14. Khan IA, Kulkarni MV, Sun CM (2005) One pot synthesis of oxygenated tri-heterocycles as anti-microbial agents. Eur J Med Chem 40(11): 11681172.

15. Laurin P, Ferroud D, Schio L, Klich M, Dupuis-Hamelin C, et al. (1999) Structure-activity relationship in two series of aminoalkyl substituted coumarin inhibitors of gyrase B. Bioorg Med Chem Lett 9(19): 28752880 .

16. Arshad A, Osman H, Bagley MC, Lam CK, Mohamad S, et al. (2011) Synthesis and antimicrobial properties of some new thiazolyl coumarin derivatives. Eur J Med Chem 46(9): 3788-3794.

17. Panchagnula R, Thomas NS (2000) Biopharmaceutics and pharmacokinetics in drug research. Int J Pharm 201(2): 131-150.

18. Daniels TC (1943) Synthetic Drugs. Annual Review of Biochemistry 12(1): 447-472.

19. Logie L, Harthill J, Patel K, Bacon S, Hamilton DL, et al. (2012) Cellular responses to the metal-binding properties of metformin. Diabetes 61(6): $1423-1433$.

20. Ahmed SM, Ismail DA (2008) Synthesis and Biological Activity of 8-Hydroxyquinoline and 2-Hydroxypyridine Quaternary Ammonium Salts. Journal of Surfactants and Detergents 11(3): 231-235.

21. Veber DF, Johnson SR, Cheng HY, Smith BR, Ward KW, et al. (2002) Molecular Properties That Influence the Oral Bioavailability of Drug Candidates. J Med Chem 45(12): 2615-2623.

22. Kulkarni MV, Patil VD (1981) Studies on coumarins, I. Arch Pharm (Weinheim) 314(8): 708-711.

23. Burger A, Ullyot GE (1947) Analgesic studies. $\beta$-ethyl and $\beta$-isopropylamine derivatives of pyridine and thiazole ${ }^{1}$. J Org Chem 12(2): 342-355.

24. Manjula SN, Kenganora M, Parihar VK, Kumar S, Nayak PG, et al. (2010) Antitumor and antioxidant activity of polyalthia longifolia stem bark ethanol extract. Pharm Biol 48(6): 690-696.

25. Ribble D, Goldstein NB, Norris DA, Shellman YG (2005) A simple technique for quantifying apoptosis in 96-well plates. BMC Biotechnol 5: 12 .

26. Schwalbe LR, Steele-Moore, AC Goodwin (2007) Anti-microbial susceptibility testing protocols. Crc Press, Florida, USA. p. 432.

27. Lourenço MCS, Marcus VN de S, Alessandra CP, Marcelle de LF, Raoni SBG, et al. (2007) Evaluation of anti-tubercular activity of nicotinic and isoniazid analogues. ARKIVOC (xv) 181-191. 